\title{
Epidemiology of goitre in Sri Lanka in the post-iodization era
}

\author{
R Fernando', A Pathmeswaran², M D P Pinto ${ }^{3}$ \\ (Index words: epidemiology, goitre, iodization, Sri Lanka)
}

\begin{abstract}
Introduction Previous studies of goitre in Sri Lanka proposed the presence of a goitre belt, which was refuted subsequently. Epidemiology of goitre in the post iodization era needs re-evaluation.

Objectives To describe the epidemiology of goitre in Sri Lanka.

Methods A descriptive cross-sectional study was conducted in designated zones except in conflict areas in $2006 / 2007$. An interviewer administered questionnaire was used and patients were evaluated clinically, biochemically and cytologically.
\end{abstract}

Results Among 5200 participans 426 had goitre. Mean age was 36.3 (SD 17.3) years. Goitre was commonest in the age group 40-49 years with a female pre-ponderance. The prevalence was similar in all zones with pockets of high prevalence in each zone. Overall islandwide adjusted prevalence was $6.8 \%(95 \% \mathrm{Cl}=6.0-7.6)$.

Conclusions There was no identifiable goitre belt.There were pockets of high prevalence in all zones. Goitre remains a public health issue despite universal iodization.

Ceylon Medical Journal 2015; 60: 41-4

\section{Introduction}

Goitre is a public health problem in certain areas of the world. Deficiency of dietary iodine is the main aetiological factor in such regions [1]. Goitre is endemic in Sri Lanka [2]. It was first described by Bennet in 1849 in the coastal regions [3]. Goitre was identified as a public health problem in Sri Lanka, following a detailed study [4].

A characteristic epidemiological pattern of a goitre belt was described in the Western, Sabaragamuwa, Southern and Uva provinces in 1967 [5]. Leaching of iodine from soil due to heavy rain fall was suggested as the possible cause. Changes from this pattern was noted, where areas of high prevalence of goitre ranging from $6 \%$ to $30 \%$ were described [2]. Subsequent studies have shown a change in prevalence, but none of these studies were population based [6]. Universal salt iodisation is a recognized strategy to overcome endemic goitre which has been implemented since 1995 in Sri Lanka. Therefore an islandwide study on the epidemiology of goitre was done to determine the epidemiology in the post-iodization era.

\section{Methods}

A descriptive cross-sectional study on epidemiology of goitre was conducted islandwide, except the Northern Province and the Batticaloa district (due to security reasons) from December 2006 to June 2007. The country was divided into six areas in three zones (Wet, Intermediate and Dry zones) based on rainfall patterns and geography (Figure 1).

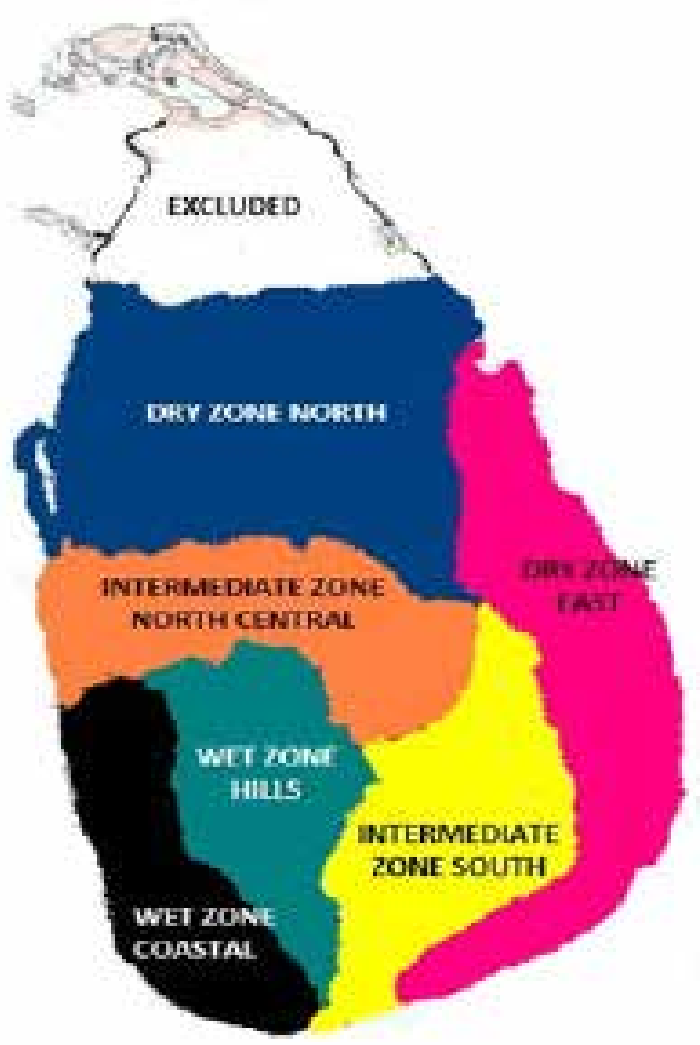

Figure 1. Division of the country into six zones based on rainfall patterns and geography.

Departments of ${ }^{1}$ Surgery and ${ }^{2}$ Public Health, University of Kelaniya, ${ }^{3}$ District General Hospital, Chilaw, Sri Lanka.

Correspondence: RF, e-mail: <ranilfern@sltnet.lk>. Received 13 October 2014 and revised version accepted 29 December 2014. 
Table 1. Prevalence of goitre by zones

\begin{tabular}{lcccc}
\hline \multicolumn{1}{c}{ Zone } & $\begin{array}{c}\text { Number } \\
\text { examined }\end{array}$ & Crude & $\begin{array}{c}\text { Prevalence } \\
\text { Adjusted }\end{array}$ & $95 \%$ CI \\
\hline Wet Zone - Coastal (Z1) & 869 & 7.83 & 6.45 & $4.87-8.02$ \\
Wet Zone - Hills (Z2) & 836 & 9.93 & 7.93 & $6.23-9.63$ \\
Dry Zone - East (Z3) & 1092 & 6.87 & 5.93 & $4.54-7.32$ \\
Dry Zone - North Central (Z4) & 989 & 7.68 & 6.65 & $5.11-8.19$ \\
Intermediate Zone - North (Z5) & 816 & 9.80 & 7.42 & $5.83-9.00$ \\
Intermediate Zone - South (Z6) & 598 & 7.19 & 5.34 & $3.76-6.92$ \\
\hline
\end{tabular}

A sample size of 865 participants in each zone was required to estimate the prevalence to within $6 \%$ with $95 \%$ confidence assuming an expected prevalence of $10 \%$. This calculation included a correction for cluster sampling (assumed design effect of 2) and a 10\% correction for non-response. This was rounded up to 900 . Grama Niladhari (GN) areas (villages) of each zone were listed and $18 \mathrm{GN}$ areas from each zone were selected using the probability proportionate to size (PPS) technique. One hundred and eight GN areas were selected for the island wide study. Individuals were selected randomly from each GN area where 5 sub clusters of 10 were selected from a householders list maintained by the Grama Niladhari (Government official) or the midwife. Children aged less than 10 years were excluded.

A pre-tested interviewer administered questionnaire consisting of demographic data, details of family history, economic status and consumption of possible goitrogenic substances was administered after obtaining verbal consent. Clinical evaluation was undertaken by two investigators and confirmed by the principal investigator. Biochemical and cytological evaluation was undertaken thereafter with written consent.

All the investigators were medical graduates who were briefed and trained on administering the questionnaire and the standard examination of goitre at the surgical clinics of Teaching Hospital, Ragama, Sri Lanka. Response rate was $100 \%$ as all individuals were interviewed by trained personnel. Data were entered into a computerised database and analysed using the STATA package. For different zones prevalence was calculated with $95 \%$ confidence interval. Participants who had their goitre operated prior to the study were not included in the calculation of prevalence.

Approval for this study was granted by the Ethics Committee of Faculty of Medicine, University of Kelaniya, Sri Lanka. Written informed consent was obtained from all participants.

\section{Results}

Out of the 5200 participants $3433(66 \%)$ were female and $1767(34 \%)$ were male. Four hundred and twenty six had goitres. Majority 283 (66.43\%) were female and 143
(33.56\%) were male. Highest prevalence was in the age group 40-49 years (Figure 2) and in the wet zone hills (7.93\%). The lowest prevalence was in the intermediate zone south (5.34\%) (Table 1). Islandwide adjusted (age and zone) prevalence of goitre among females was $11.2 \%$ and males was $2.3 \%$. Prevalence was similar throughout the country. Overall adjusted prevalence in the country was $6.8 \%(95 \% \mathrm{CI}=6.0-7.6)$. Instead of a goitre belt, there were $\mathrm{GN}$ areas in all zones where the prevalence exceeded $10 \%$. There were 28 pockets with high prevalence of goitre in all 6 climatic zones (Table 2). Highest prevalence of $21.6 \%$ was in Kokmaduwa in Zone 4. In each zone there were at least two or more pockets of high prevalence of goitre (Figure 3).

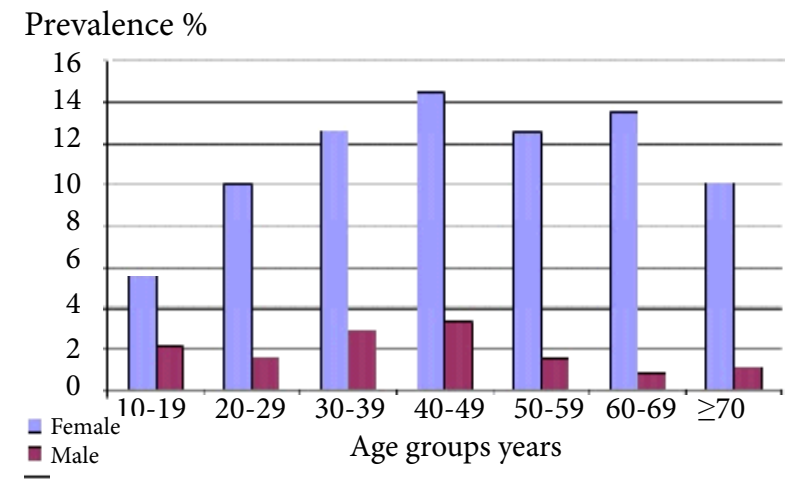

Figure 2. Prevalence of goitre by age and sex.

Table 2. Pockets of high prevalence in different zones

\begin{tabular}{lcc}
\hline \multicolumn{1}{c}{ Zone } & Number of pockets & Prevalence \\
\hline Z1-Wet Zone Coastal & 3 & 10.7 \\
Z2-Wet Zone Hills & 6 & 21.4 \\
Z3-Dry Zone East & 5 & 17.7 \\
Z4-Dry Zone North Central & 6 & 21.4 \\
Z5-Intermediate Zone North & 6 & 21.4 \\
Z6-Intermediate Zone South & 2 & 7.1 \\
Total & 28 & 100.0 \\
\hline
\end{tabular}




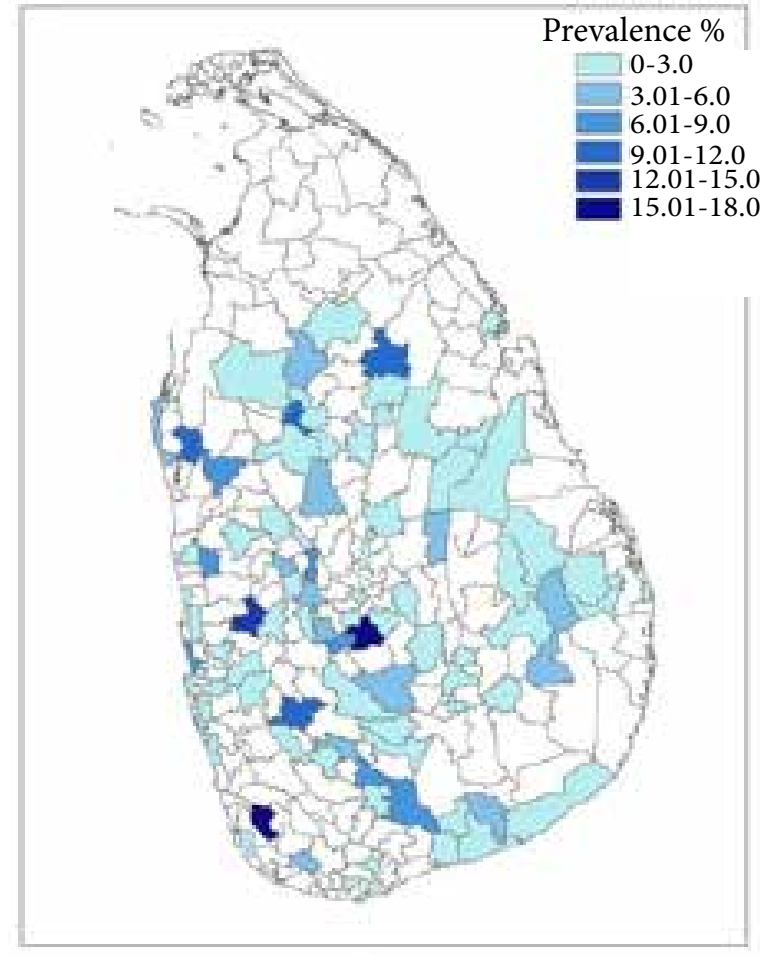

A

Goitre prevalence in males in selected DS divisions

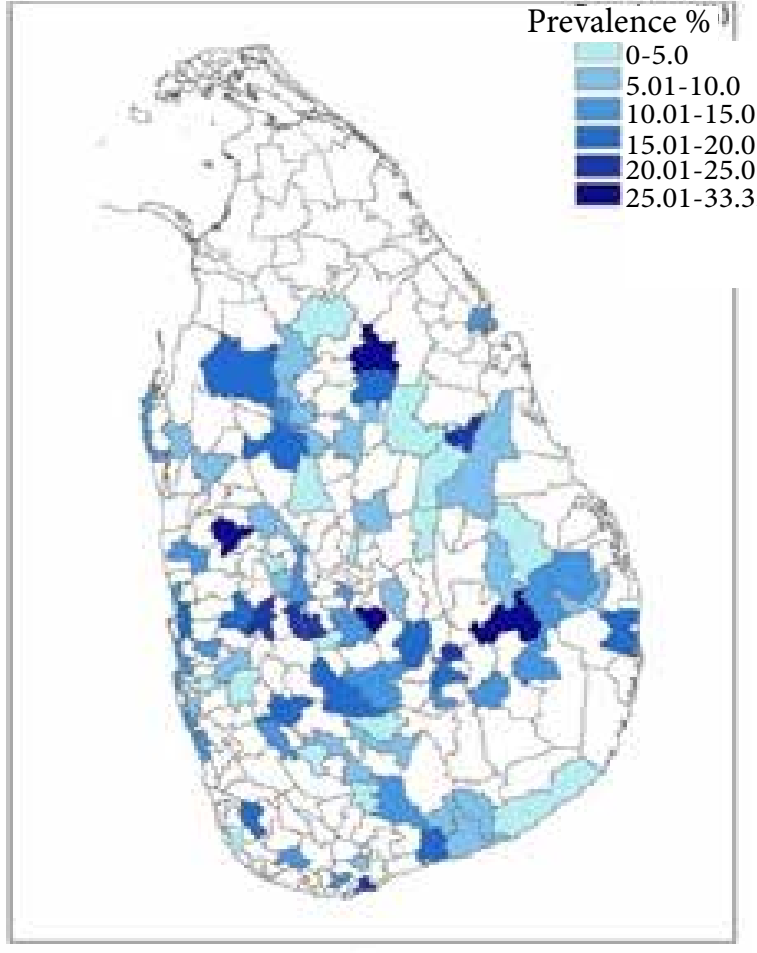

B

Goitre prevalence in females in selected DS divisions

Figure 3. Prevalence of goitre in selected District Secretarial divisions.

\section{Discussion}

Goitre is endemic if the prevalence is more than 5\% [6]. Goitre was a public health issue in Sri Lanka. Universal iodization of salt was implemented in Sri Lanka in 1995 as iodine deficiency was considered the main aetiological factor for goitre [7]. Varying prevalence rates have been noted in previous studies. A previous study showed that prevalence of goitre was $18.8 \%$ among school children in 17 districts out of 24 in the country and refuted the presence of a goitre belt and suggested pockets of high prevalence [2]. More recently a study done across the country among school children aged 8-10 years showed a low prevalence of goitre [8].

As reported in previous studies female preponderance of goitre was noted in all zones. Goitres were commonest in the 40-49 years age group. More females were interviewed than males during the study, but adjustment was made when calculating the prevalence. The adjusted prevalence varied between $5.93 \%$ to $7.93 \%$ in the different climatic zones. There was little variation which suggests that the prevalence of goitre is similar throughout the country.

Areas of high prevalence of goitre or 'pockets' were seen in all 6 climatic zones of the country (Table 2). There were 28 pockets where prevalence was higher than $10 \%$ and in some, prevalence was more than $15 \%$. Kokmaduwa in the Dry Zone-North Central had the highest prevalence of $21.6 \%$. While variation in sampling can give rise to high prevalence in some areas, a prevalence of more than three times the national average cannot be explained by this.

With the country achieving nearly $99 \%$ success rate in salt iodization, iodine deficiency can no longer be considered the main aetiological factor for goitre in Sri Lanka. The persistence of a prevalence rate of $6.8 \%$ despite adequate iodization and the pockets of high prevalence needs to be studied carefully. Despite universal iodization for over 15 years, goitre remains a public health issue in Sri Lanka.

The age and sex corrected islandwide prevalence rate of goitre in the population over 10 years of age was $6.8 \%$ ( $95 \% \mathrm{CI}=6.0 \%-7.6 \%)$. There was widespread prevalence of goitre across the country with no evidence of a goitre belt. Pockets of high prevalence as high as $25 \%$ were noted in all 6 zones,which requires further study.

\section{Acknowledgements}

We acknowledge the valuable advice given by Professor L. Rajapaksa and support given by re-search assistants S Abeysinghe, N Athulugama, D Bandara, 
D Edirisinghe, S Fernando and M Premathilake. The study was funded by a grant from the National Science Foundation, Sri Lanka.

\section{Conflicts of interest}

We declare that there are no conflicts of interest.

\section{References}

1. Andersson M, Takkouche B, Egli I, et al. Current global iodine status and progress over the last decade towards the elimination of iodine deficiency. Bull World Health Organ 2005; 83: 518-25.

2. Fernando MA, Balasuriya S, Herath KB, et al. Endemic Goitre in Sri Lanka. Asia Pac J Public Health 1989; 3:11-8.
3. Benett M. Ceylon and its Capabilities. National Archives in Sri Lanka. London W. M. H. Allen and Co: Laden Hall Street 1849: 856-60.

4. Wilson DC. Goitre in Ceylon and Nigeria. Br J Nutr 1954; 8: $90-9$.

5. Mahadeva K, Shanmuganathan SS. The problem of goitre in Ceylon. Br J Nutr 1967; 21: 341-52.

6. WHO, UNICEF, ICCIDD team. Assessment of Iodine deficiency disorders and monitoring their elimination. 2nd ed. WHO/NHD/01.1 2001: 36-40, 49-56.

7. Jayatissa R, Gunathilaka MM, Fernando DN. Iodine nutrition status among school children after salt iodisation. Ceylon Med J 2005; 50: 144-6.

8. Jayatissa R, Gunathilaka MM, Fernando DN. Iodine nutrition status among schoolchildren after salt iodisation. Ceylon Med J 2005; 50: 144-8. 